\title{
Rodent-mediated plant community competition: what happens to the seeds after entering the adjacent stands?
}

\author{
Haibin Kang ${ }^{1}$, Mingjie Chang ${ }^{1}$, Shutong Liu' ${ }^{1}, Z_{\text {Zhi Chao }}^{1}$, Xinping Zhang ${ }^{1,2}$ and Dexiang Wang ${ }^{1 *}$ (D)
}

\begin{abstract}
Background: Seed dispersal by scatter-hoarding animals can affect the developmental dynamics of plant communities. However, how animals might participate in plant inter-community competition has rarely been investigated. Forest community junction is an area where the competition between plant communities is most prominent and animal activity is more frequent. At present, little is known about how scatter-hoarding animals might assist competitions by adjacent plant communities. Thus, for 3 years (2015-2017), we tracked the fate of 2880 tagged seeds (Quercus aliena var. acuteserrata, Pinus tabuliformis, and P. armandii seed) placed near an edge where the forest composition changes from a pine forest to an oak forest in northwestern China.

Results: We found that the seed fates differed when Quercus and Pinus seeds entered adjacent stands. In contrast to Pinus seeds, acorns that entered pine forests were characterized by higher caching rates and longer dispersal distances. Pinus seeds had the highest probability of being predated (85\%) by rodents, and eleven Q. aliena var. acuteserrata seedlings were established in pine forests, although none survived in the later stages. In addition, rodents exhibited obvious selectivity in terms of the microhabitats for the seed caching sites.
\end{abstract}

Conclusions: Seed fates differed when Quercus and Pinus seeds entered adjacent stands. The predation pressure by rodents on the seeds of Pinus species limited the germination of seeds and seedling establishment in oak forests. The different seed fates after their bidirectional dispersal could affect the differences in natural regeneration between pine and oak forests, and they might increase the recruitment rates for oak at the edge of an adjacent community. Rodent-mediated seed dispersal could potential unintentionally affect the competition between plant communities.

Keywords: Pine-oak mixed forest, Plant community competition, Scatter hoarding, Seed dispersal, Small rodent

\section{Background}

Forests provide an important food source for animals and these animals also influence the spatial structure of the plant population, community assembly, and forest dynamics through their inconspicuous foraging behavior (Wang and Chen 2009; Vander Wall 2010; Spiegel and Ran 2012; Lichti et al. 2017). Rodent-mediated seed dispersal can be regarded as an important process in the regeneration, survival, and distribution of plant species. In general, scatter-hoarding animals subsist on seeds during

\footnotetext{
*Correspondence: wangdx66@sohu.com

${ }^{1}$ College of Forestry, Northwest A \& F University, Yangling 712100, China

Full list of author information is available at the end of the article
}

some or all of the year (Vander Wall and Beck 2012), they play crucial roles in seed dispersal, where they can indirectly facilitate long-term seed germination and natural regeneration (Zhang et al. 2013; Yu et al. 2014), while successful natural regeneration is the foundation of healthy forest development (Yan et al. 2016).

Rodent-mediated seed dispersal is a crucial secondary dispersal process after seeds leave the parent tree falling to the ground (Vander Wall 2003), where it indirectly affects natural forest regeneration and the plant community structure (Vander Wall 1990; Vander Wall 2010). It is generally accepted that seed dispersal by rodents can help seeds to reach a more suitable position for 
germination compared with undispersed seeds that remain below the parent tree (Vander Wall 1993; Yu et al. 2014; Wang and Corlett 2017). The spatial distribution of scatter hoards by scatter-hoarding animals represents a trade-off between the energy invested in establishing caches and the increased risk of pilferage (Steele et al. 2015; Yang et al. 2016; Dylewski et al. 2020). Some seeds that escape predation are more likely to be recruited successfully if the burial position is in a suitable habitat. When the ambient food availability is higher than the size of the animal population, scatter-hoarding animals are less dependent on stored seeds, and thus many cached seeds will escape predation (Vander Wall 2002; Bergeron et al. 2011; Soler et al. 2017). However, the overall effect of scatter-hoarding animals on seed dispersal and seedling recruitment is conditionally mutualistic (Xiao and Krebs 2015; Lichti et al. 2017). This mutualistic relationship between the plant community and scatter-hoarding animals is affected by various biotic and abiotic factors in forest ecosystems, such as predation, forest habitat, and human disturbance ( $\mathrm{Yu}$ et al. 2015; Kellner et al. 2016).

The reciprocal relationship between rodents and plants community varies in different forest habitat, it is particularly important to understand the role of scatterhoarding animals in plant inter-community competition. Forest community junction is considered a unique environment, it is an area where the competition between plant communities is most prominent (Kang et al. 2017) and animal activity is more frequent because of the greater diversity and abundance of food resources (Yu et al. 2018). Many previous studies have investigated the ecological process, stand development dynamic and population characteristics of plant community junction (Gracia et al. 2002; Mendes et al. 2016; Kang et al. 2017), whereas few have considered the relationships among animals and plant community competition according to their foraging behavior. Thus, it would be useful to determine whether scatter-hoarding behavior and cache establishment by animals might act as a driving force to help species infiltrate adjacent communities.

Pine-oak (Pinus-Quercus) mixed forests are the dominant forest type in the Qinling Mountains, China, where the pine and oak forests exhibit patch mosaic spatial distributions at the landscape scale. In general, mixed forests exhibit high species richness and distinctive species compositions, and they have essential roles in maintaining biodiversity and ecosystem functions (Stone 2006). Previous studies have indicated that competition gradually increases with the development of populations in the edge between pine and oak forests, where Pinus species are considered to be the pioneer species during succession and they are usually invaded by late successional Quercus species (Gracia et al. 2002; Yu et al. 2014; Kang et al.
2017). However, the mechanism responsible for driving the invasion process is not well understood. Some of the gaps that frequently form in the Qinling pine forest due to disturbances (such as steal cutting, wild fire and wind) are eventually supplemented by oaks (those phenomena according to personal investigations and inquiries from local forest managers). Some oak seedlings were found in pine forests at the top of mountains during our previous survey, which could not be reached by gravity dispersal due to the topography. Therefore, the appearance of oaks in pine forests may be due to complex environmental effects where animal assistance may mediate their initial invasion of pine forests, thereby suggesting that the competition among animals may participate in the development of plant communities. Yu et al. (2014) documented that over $30 \%$ of the released acorns were dispersed by rodents into the $P$. armandii stands where they established some seedlings. Moreover, seed dispersal and seedling recruit successfully is also influenced by biotic (seed ripening season, seed quality, seed size, pericarp thickness, predator age, predator preferences, community type, vegetation under the canopy, etc.) (Wang and Chen 2009; Vander Wall 2010; Santos-Filho et al. 2012; Zhou et al. 2013; Yu et al. 2015; Bartlow et al. 2017; Soler et al. 2017; Wang and Corlett 2017; Dylewski et al. 2020) and abiotic factors (e.g., soil moisture, light, temperature, slope) (Garcia et al. 2002; Yu et al. 2013). Most previous studies of seed dispersal only considered animal behavior and few investigated the relationships between animals and plant community dynamics based on the long-term tracking of the survival dynamics of seedlings that germinate after burial by rodents. Therefore, determining whether small animals play a major role in the forest succession process may provide insights into how oak invades pine forests.

The invasion behavior of many plant species depends greatly on the propagule pressure (Lonsdale 1999; Clair et al. 2016; Wróbel and Zwolak 2019), and a previous study showed that Quercus aliena var. acuteserrata forest has a natural regeneration bottleneck (Kang et al. 2017). To better understand the community competition and driving forces responsible for the invasion of oak into pine forests, and how different forest communities affect the dispersal and fate of seeds from adjacent communities, we selected a mosaic region of pine-oak mixed forest in the Qinling mountains and simultaneously cross-released seeds of each type in the opposing forest stands to simulate seed dispersal, before determining the fates of the seeds that entered the stands, i.e. the performance of seeds after entering the adjacent stands. Here, the seed dispersal drivers include both abiotic (e.g., wind) and biotic (e.g., rodents, jay) factors. We also measured the forest structure in the two communities to identify changes that might affect acorn predation and dispersal, and tracked the germination and growth of the 
seeds cached by rodents over 3 years. We also measured seed production in the pine and oak forest to consider the possible variability in ambient food availability. We addressed the following questions: (1) Do forest rodents influence the seed dispersal patterns of pine seeds and oak seeds that enter stands of each other? (2) How do forest rodents influence the natural regeneration and developmental dynamics of pine-oak mixed forests? Thus, we aimed to determine the effects of rodent-mediated seed dispersal on the plant community competition in a typical pine-oak mosaic mixed forest to provide a theoretical basis for plant community system and forest management, especially maintaining the stability of mixed forests.

\section{Methods}

\section{Study site and species}

The experiments were conducted during the autumn (October-December) of 2015 in the Huoditang forest region $\left(108^{\circ} 21^{\prime}-108^{\circ} 29^{\prime} \mathrm{E}, 33^{\circ} 18^{\prime}-33^{\circ} 28^{\prime} \mathrm{N}\right)$, Shaanxi Province, northwestern China. The forest region is located in the middle of the Qinling Mountains, which are characterized by a moist temperate climate. The annual precipitation ranges from 1000 to $1200 \mathrm{~mm}$, and it is distributed fairly unevenly throughout the year, but most falls from July to September. The average temperature ranges from $8{ }^{\circ} \mathrm{C}$ to $10^{\circ} \mathrm{C}$, with a maximum of $28.6^{\circ} \mathrm{C}$ in July and a minimum of $-9.5^{\circ} \mathrm{C}$ in January ( $\mathrm{Yu}$ et al. 2013). The vegetation mainly comprises mixed conifer and deciduous forests, as well as conifer forests, where the forest coverage rate is $93.8 \%$. The dominant tree species are Q. aliena var. acuteserrata, Pinus tabuliformis, P. armandii, Q. variabilis, Tsuga chinensis, Carpinus turczaninowii, Betula albosinensis, and Acer davidii. Pine-oak (Pinus-Quercus) mixed forests are the dominant forest type in this region. The rodent species composition varied at the study site but the dominant species were Apodemus draco, A. peninsulae, Sciurotamias davidianus, and Niviventer confucianus (Chang et al. 2012; Yu et al. 2014).

\section{Seed disperser identification}

After field reconnaissance, a forest edge between oak and pine plant communities was selected in a typical pine-oak mosaic mixed forests in the Huoditang forest region. Whitmore's characterization of the forest mosaic to distinguish between two types of patches was used (Whitmore 1978), i.e., pine forests dominated by $P$. tabuliformis and $P$. armandii and oak forests dominated by $Q$. aliena var. acuteserrata. The sample plot-specific factors, ground vegetation, total coverage, and natural regeneration were measured according to the "Observation Methodology for Long-term Forest Ecosystem Research" in the National Standards of the People's
Republic of China (GB/T 33027-2016). We used 30 live wire cage traps $(27 \mathrm{~cm} \times 14 \mathrm{~cm} \times 11 \mathrm{~cm})$ baited with peanuts and melon seeds to verify the abundances and species composition of rodents at the study site after the seed dispersal experiment. All of the steel wire traps were placed in $P$. armandii-P. tabuliformis forests (pine forests) and $Q$. aliena var. acuteserrata forests (oak forests) along each of two transects at an interval of $5 \mathrm{~m}$ apart during November 14-18, 2015. The traps were opened in the same direction and checked every day at sunrise after the experiment commenced. This experiment was conducted for four consecutive days. The total number of trapping days and nights was 150 (15 traps $\times$ two transects $\times 5$ days and nights) for the plot. Trap success $(\%)=($ trapped individuals $/$ trap nights $) \times 100 \%$. The captive animals were identified, weighed, and photographed, and then released in situ immediately.

\section{Seed production survey}

During 2015 and 2016 (August-November), we collected seeds from $Q$. aliena var. acuteserrata, P. tabuliformis, and $P$. armandii using seed traps in the plot in order to analyze the seed crops. Three transect lines were set at the centers of the pine forests and oak forests to determine the production rate and distribution of seeds in the plot. Ten traps were spaced $10 \mathrm{~m}$ apart along each transect, which were separated by $15 \mathrm{~m}$. In total, we placed 60 traps (10 traps $\times$ three transects $\times$ two forests) in the plot (Fig. S1). Each trap had a diameter of $79.8 \mathrm{~cm}$ and it was set about $1 \mathrm{~m}$ above the ground using three bamboo poles to reduce the interference from animals. The seed traps comprised nylon net $(1 \mathrm{~mm}$ mesh $)$ and iron wire (diameter $=4.1 \mathrm{~mm})$, with a collection area of $0.5 \mathrm{~m}^{2}$. The traps collected seeds that were as small as possible but without being destroyed by the rain or snow. When the seed rain commenced, we regularly collected seeds from 60 traps and transported them to the laboratory for counting and identification each year. Seed rain density $\left(\mathrm{m}^{-2}\right)=$ seed amount/seed trap area.

\section{Seed preparation}

During the seed rain from Q. aliena var. acuteserrata, mature and fresh Q. aliena var. acuteserrata acorns were collected near the study site for the seed dispersal experiment. Water flotation and visual examination were used to identify sound and insect-damaged/empty acorns. Q. aliena var. acuteserrata acorns are oval and vary considerably in size. Thus, we selected 720 fresh and sound large $Q$. aliena var. acuteserrata acorns $(1.692 \pm 0.033 \mathrm{~g}$ mass; $22.485 \pm 0.114 \mathrm{~mm}$ long, $13.821 \pm$ $0.072 \mathrm{~mm}$ wide, mean \pm standard error, $n=100$ ) and 720 small Q. aliena var. acuteserrata acorns $(0.733 \pm 0.018 \mathrm{~g}$ mass; $15.131 \pm 0.151 \mathrm{~mm}$ long, $9.271 \pm 0.095 \mathrm{~mm}$ wide) 
(total of 1440 seeds). It was designed to compare the performance of acorns of different sizes after entering the pine forest in order to assess the relationship between the seed size and rodents. Mature and fresh $P$. armandii and P. tabuliformis pine cones collected in the fall of 2015 were bought from local farmers. We selected 720 fresh and sound $P$. armandii seeds weighing $0.274 \pm$ $0.006 \mathrm{~g}$ and 720 fresh and sound P. tabuliformis seeds weighing $0.022 \pm 0.001 \mathrm{~g}$ (total of 1440 seeds). Coded plastic tags (Yi and Zhang 2008) were used to study the dispersal of $Q$. aliena var. acuteserrata, $P$. armandii, and $P$. tabuliformis seeds. A tiny hole measuring $0.3 \mathrm{~mm}$ in diameter was drilled through the husk away from the cotyledon and embryo in each seed, and a white plastic tag $(3.0 \mathrm{~cm} \times 2.0 \mathrm{~cm},<0.1 \mathrm{~g})$ was tied through the hole in each seed using a steel thread with a diameter of 0.3 $\mathrm{mm}$ and length of $12 \mathrm{~cm}$. Tagging has been shown to have a negligible effect on seed removal and hoarding by rodents (Xiao et al. 2006). For each plastic tag, we recorded the seed site, seed category, seed number, and other information in order to ensure that each seed could be tracked.

\section{Seed release}

In the plot, eight transect lines were placed vertically along the boundary of the forest edge between pine and oak forests, and six seed stations were established on each transect line at intervals of $10 \mathrm{~m}$ apart. Each of the seed stations was set as a distance group, i.e., 0, 10, 20, 30,40 and $50 \mathrm{~m}$, which were the distances from the forest edge between the pine and oak forests (Fig. S1). The large and small Q. aliena var. acuteserrata acorns were placed at each seed station in the pine forests, and $P$. armandii and $P$. tabuliformis seeds were placed at each seed station in the oak forests. Thirty tagged seeds from each species $(1-2 \mathrm{~m})$ were placed separately at each seed station. The total number of seeds released was eight $($ transects $) \times \operatorname{six} \quad($ stations $) \times 60 \quad($ seeds $)=2880 \quad$ tagged seeds. We checked the seed stations every other day after seed release, and searched the area around each seed station as well as possible to classify the fates of all the released seeds according to six categories (Yi and Zhang 2008): (1) intact in situ (IIS), (2) eaten in situ (EIS), (3) eaten after removal (EAR), (4) intact but not buried after removal to another location (IAR), (5) scatter hoarding after removal $(\mathrm{SH})$, and (6) missing (M) when we could not find them and were unable to determine their fates. When a seed was removed, we carefully noted the seed code number and measured the distance and direction of the tagged seed from its original seed station. The microhabitats were recorded for IAR and $\mathrm{SH}$ seeds, where five categories of microhabitats were classified as follows ( $\mathrm{Li}$ and Zhang 2003): (1) under shrub, (2) shrub edge, (3) hole, (4) grassland, and (5) bare land. The successful seedlings at the cache sites selected by rodents were tracked in 2016 and 2017. In addition, we measured the basal diameter, height, and leaf number of each seedling to evaluate the seedling growth and vitality.

\section{Statistical analysis}

Data analysis was conducted using SPSS for Windows version 21.0. To ensure normality and homogeneity of variance, the proportions of remaining, eaten, and cached seeds were arc-sine transformed before statistical analysis. The $X^{2}$ test was used to compare the differences in the rodent species among the two types of forests. Paired-sample $t$-tests were used to detect the differences in the seed crops from $Q$. aliena var. acuteserrata, $P$. armandii, and $P$. tabuliformis in the two years. Cox regression analysis was used to compare the times until removal from the seed stations for the four seed types in pine and oak forests. We analyzed the seed fate and dispersal distance based on the seed tracking experiments. Generalized linear models were used to test differences in the seed rates for IIS, EIS, EAR, IAR, SH among the four seed types as well as the effects of distance groups on the removal distance. Tukey's HSD post hoc tests were applied for multiple comparisons of seed fates between the six distance groups. Two-way analysis of variance was used to test the interactions between seed species and distance group. Data were expressed as the mean \pm standard error.

\section{Results}

\section{Rodent abundances}

The results obtained from the seed disperser identification experiments were based on 30 live steel-wire traps (15 each in pine and oak forests). Three rodent species were trapped during 150 trap days and nights with a trap success rate of $34.00 \%$. In total, 26 and 25 rodents were captured in the pine and oak forests, respectively (Table 1), and the rodent species and capture rates did not differ between the two forests $\left(\chi^{2}=0.267, d f=1, P>\right.$ 0.05). Apodemus peninsulae was the dominant species in the pine and oak forests, where it accounted for $57.69 \%$ and $80.0 \%$ of the rodents trapped, respectively.

\section{Seed crops}

There were significant differences in the seed crops between 2015 and 2016 for each of the three species (all $P<0.001)$. Furthermore, the seed crops from pine forests and oak forests differed significantly in 2015 and 2016 (2015: $t=-3.048, d f=29, P=0.005 ; 2016: t=-11.554$, $d f=29, P<0.001)$. The seed crops from $Q$. aliena var. acuteserrata, $P$. armandii, and $P$. tabuliformis were $33.20 \pm 4.07 \mathrm{~m}^{-2}, 22.47 \pm 9.19 \mathrm{~m}^{-2}$, and $18.33 \pm 2.35 \mathrm{~m}^{-2}$ 
Table 1 Number of small rodents captured ( $n=150$ trap days and nights) in the plot

\begin{tabular}{|c|c|c|c|c|}
\hline \multirow[t]{2}{*}{ Species } & \multicolumn{2}{|l|}{ Pine forests } & \multicolumn{2}{|l|}{ Oak forests } \\
\hline & Trapped individuals & Trap success (\%) & Trapped individuals & Trap success (\%) \\
\hline Apodemus peninsulae & 15 & 20.0 & 20 & 26.7 \\
\hline A. draco & 7 & 9.3 & 3 & 4.0 \\
\hline Sciurotamias davidianus & 4 & 5.3 & 2 & 2.7 \\
\hline Total & 26 & 34.6 & 25 & 33.4 \\
\hline
\end{tabular}

in 2015, respectively, and $4.40 \pm 0.5 \mathrm{~m}^{-2}, 1.93 \pm 0.61$ $\mathrm{m}^{-2}$, and $1.13 \pm 0.69 \mathrm{~m}^{-2}$ in 2016 (Table 2).

\section{Removal rates from seed stations}

The tagged seeds were generally removed by small rodents within 25 days of their release in the plot (Fig. 1). However, there were differences in the seed dispersal rates by rodents for the different seeds in pine and oak forests. Cox regression analysis indicated that there was no significant difference in the seed removal rates for large and small Q. aliena var. acuteserrata acorns in pine forests ( Wald $=3.576, d f=1, P=0.059$ ). By contrast, there was a significant difference in the seed removal rates for $P$. armandii seeds and $P$. tabuliformis in oak forests $($ Wald $=31.660, d f=1, P<0.001)$.

\section{Seed fates}

The proportion of small Q. aliena var. acuteserrata seeds classified as EIS was higher than that for large $Q$. aliena var. acuteserrata seeds $(45.42 \% \pm 3.48 \%$ compared with $23.61 \% \pm 2.93 \%$, respectively), and more large $Q$. aliena var. acuteserrata seeds were classified as EAR and $\mathrm{SH}$ than small Q. aliena var. acuteserrata seeds in pine forests $(47.64 \% \pm 3.09 \%$ compared with $32.50 \% \pm 3.04 \%$ for EAR, respectively, and $17.36 \% \pm 3.68 \%$ compared with $7.78 \% \pm 1.98 \%$ for $\mathrm{SH})$. The seed fate proportions for EIS, EAR, SH and $M$ differed among the two types of seeds in pine forests (EIS: $F=22.560, d f=1, P<0.001$; EAR: $F=12.120, d f=1, P=0.001 ; \mathrm{SH}: F=4.145, d f=1$, $P=0.048$; M: $F=4.437, d f=1, P=0.041$ ) (Fig. 2). In oak forests, the seed fate proportions for EIS, EAR, IAR, SH, and $M$ differed among the two species (EIS: $F=137.40$, $d f=1, P<0.001$; EAR: $F=95.340, d f=1, P<0.001$; IAR:
$F=92.17, \quad d f=1, \quad P<0.001 ;$ SH: $F=9.282, \quad d f=1, \quad P=$ 0.004; M: $F=36.40, d f=1, P<0.001$ ) (Fig. 2). The predation rates (EIS and EAR) of pine seeds in oak forests $(85.49 \pm 2.46 \%)$ were significantly higher than those of oak seeds in pine forests $(74.58 \pm 2.81 \%)$.

In the dispersal prophase ( 2 days after release), the proportions of large acorns classified as $\mathrm{SH}$ and $\mathrm{M}$ differed among the distance groups (SH: $F=3.075, d f=5, P=$ 0.035; M: $F=3.854, d f=5, P=0.015)$, where the $\mathrm{SH}$ rates for large acorns were markedly higher in the $0 \mathrm{~m}$ distance group than the 10 and $20 \mathrm{~m}$ distance groups $(P<0.05)$, and the $M$ rates for large acorns were significantly higher in the $10 \mathrm{~m}$ distance group than the 40 and $50 \mathrm{~m}$ distance groups $(P<0.05)$. In addition, there were no significant differences in the other seed fates of the four seed types among the different distance groups (all $P>0.05$ ). By contrast, in the dispersal anaphase ( 25 days after release), the proportions of large acorns classified as $M$ differed among the distance groups $(F=7.753, d f=5, P<0.001)$, where the $M$ rates for large acorns were significantly higher in the $10 \mathrm{~m}$ distance group than all of the distance groups except $30 \mathrm{~m}(P<0.05)$. The fates of the other seed types did not differ significantly among the distance groups during the dispersal anaphase (all $P>0.05$ ) (Fig. 3). In pine forests, the proportions of acorns classified as EIS differed at $30 \mathrm{~m}(F=14.35, d f=1, P=0.009), 40 \mathrm{~m}(F=6.064, d f=$ $1, P=0.049)$ and $50 \mathrm{~m}(F=6.33, d f=1, P=0.046)$, those classified as EAR differed at $20 \mathrm{~m}(F=15.32, d f=1, P=$ $0.008)$ and $30 \mathrm{~m}(F=30.54, d f=1, P=0.001)$, those classified as $\mathrm{SH}$ differed at $30 \mathrm{~m}(F=6.542, d f=1, P=0.043)$ and $50 \mathrm{~m}(F=6.386, d f=1, P=0.045)$, and those classified as $M$ differed at $40 \mathrm{~m}(F=9.069, d f=1, P=0.024)$ between the large and small acorns during the seed dispersal

Table 2 Seed densities and abundances in pine forests and oak forests during 2015 and 2016

\begin{tabular}{|c|c|c|c|c|c|c|}
\hline \multirow[t]{2}{*}{ Forest } & \multirow[t]{2}{*}{ Species } & \multirow[t]{2}{*}{ Seed category } & \multicolumn{2}{|l|}{2015} & \multicolumn{2}{|l|}{2016} \\
\hline & & & Seed amount & Seed density $\left(\mathrm{m}^{-2}\right)$ & Seed mount & Seed density $\left(\mathrm{m}^{-2}\right)$ \\
\hline \multirow[t]{3}{*}{ Pine forests } & Pinus armandii & Sound & 337 & $22.47 \pm 9.19$ & 29 & $1.93 \pm 0.61$ \\
\hline & \multirow[t]{2}{*}{ P. tabuliformis } & Sound & 275 & $18.33 \pm 2.35$ & 17 & $1.13 \pm 0.69$ \\
\hline & & Total & 612 & $40.80 \pm 9.02$ & 46 & $3.07 \pm 0.88$ \\
\hline \multirow[t]{3}{*}{ Oak forests } & \multirow{3}{*}{$\begin{array}{l}\text { Quercus aliena } \\
\text { var. acuteserrata }\end{array}$} & Sound & 498 & $33.20 \pm 4.07$ & 66 & $4.40 \pm 0.50$ \\
\hline & & Cupule & 567 & $37.80 \pm 5.34$ & 293 & $19.53 \pm 1.43$ \\
\hline & & Total & 1065 & $71.00 \pm 9.18$ & 359 & $23.93 \pm 1.58$ \\
\hline
\end{tabular}




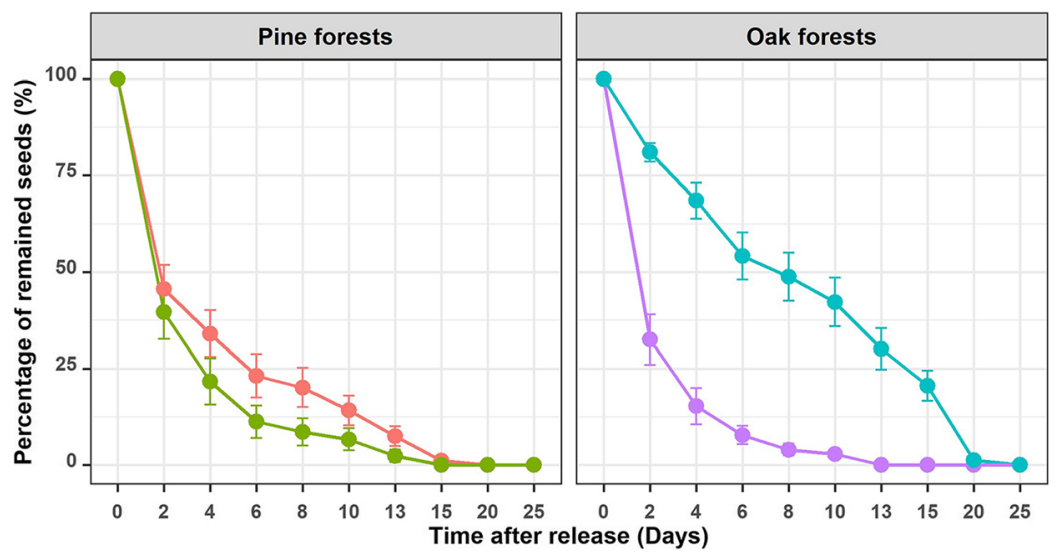

Seed type

-O QA(L)

- - QA(S)

- PA

- - PT

Fig. 1 Seed removal rates for four types of seeds after they were placed at seed stations in the study area. Data are expressed as mean \pm standard error. QA(L), Quercus aliena var. acuteserrata (large); QA(S), Quercus aliena var. acuteserrata (small); PA, Pinus armandii; PT, P. tabuliformis

anaphase. In oak forests, the proportions of seeds classified as EIS and EAR differed in all of the distance groups (all $P<0.05)$, those classified as IAR differed at $0 \mathrm{~m}(F=$ 366.1 $d f=1, P<0.001), 20 \mathrm{~m}(F=122.1, d f=1, P<0.001)$, and $50 \mathrm{~m}(F=125.6, d f=1, P<0.001)$, and those classified as $\mathrm{M}$ differed at $0 \mathrm{~m}(F=10.14, d f=1, P=0.019), 40 \mathrm{~m}$ $(F=9.0, d f=1, P=0.024)$ and $50 \mathrm{~m}(F=236.63, d f=1, P=$ 0.003 ) among the two pine seed species during the seed dispersal anaphase. Moreover, the interaction between seed type and distance group was not significant during the dispersal prophase and anaphase in oak forests, but the seed fate of SH was significantly different during the dispersal prophase $(F=4.198, d f=5, P=0.004)$ and anaphase $(F=3.246, d f=5, P=0.016)$ in pine forests.

In addition, a higher proportion of the acorns in pine forests were removed (EAR, $\mathrm{SH}$, and $\mathrm{M}$ ) by rodents in the 0,10 , and $20 \mathrm{~m}$ distance groups compared with the other groups, and the highest eaten in situ rates (EIS) were found in the 20 and $30 \mathrm{~m}$ distance groups (Fig. 4). Higher proportions of acorns were discarded after removal (IAR) by rodents in the 40 and $50 \mathrm{~m}$ distance groups compared with the other groups. The highest predation rates in oak forests occurred in the 30 and 50 $\mathrm{m}$ distance groups, and higher proportions of pine seeds were removed (EAR, IAR, $\mathrm{SH}$, and $\mathrm{M}$ ) by rodents in the 0,10 , and 20 m groups.

\section{Seed dispersal distances}

Most of the four seed types in the different distance groups were dispersed less than $10 \mathrm{~m}$ in the plot (Fig. 5). Most of the P. tabuliformis seeds were dispersed less than $1 \mathrm{~m}$ in all of the distance groups. After statistically considering the effect of average dispersal by seed types, as predicted, we found that there were significant differences in the average dispersal distances among the seed species at all seed stations in pine and oak forests (all
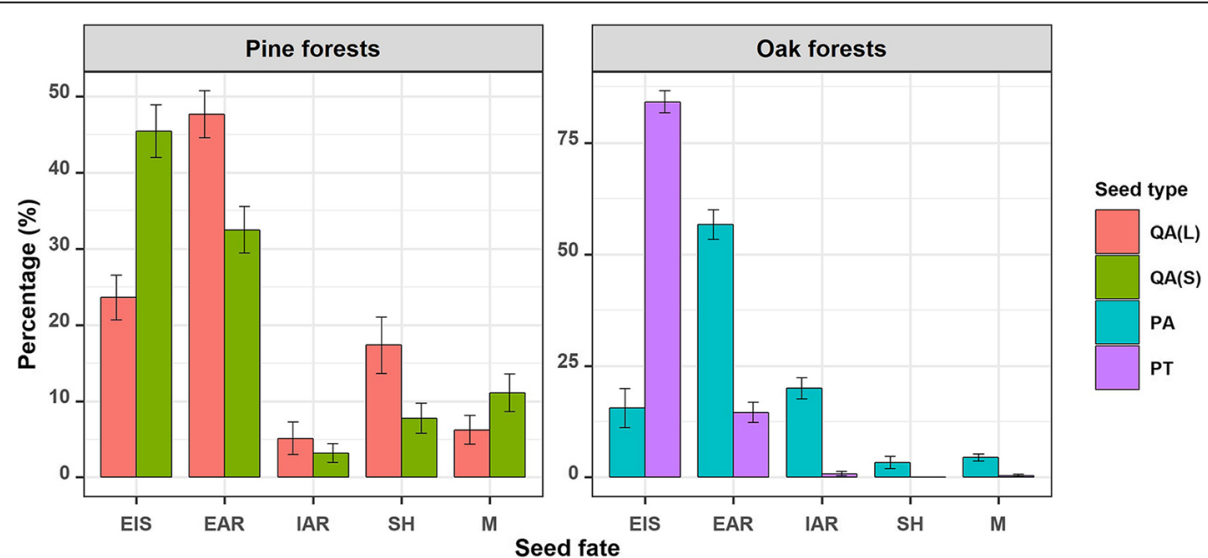

Fig. 2 Fates of four seeds types after dispersal by small rodents in the study area. Data are expressed as mean \pm standard error. EIS, eaten in situ; EAR, eaten after removal; IAR, intact but not buried after removal to another location; SH, scatter hoarding after removal; M, missing when we could not find them and were unable to determine their fates 


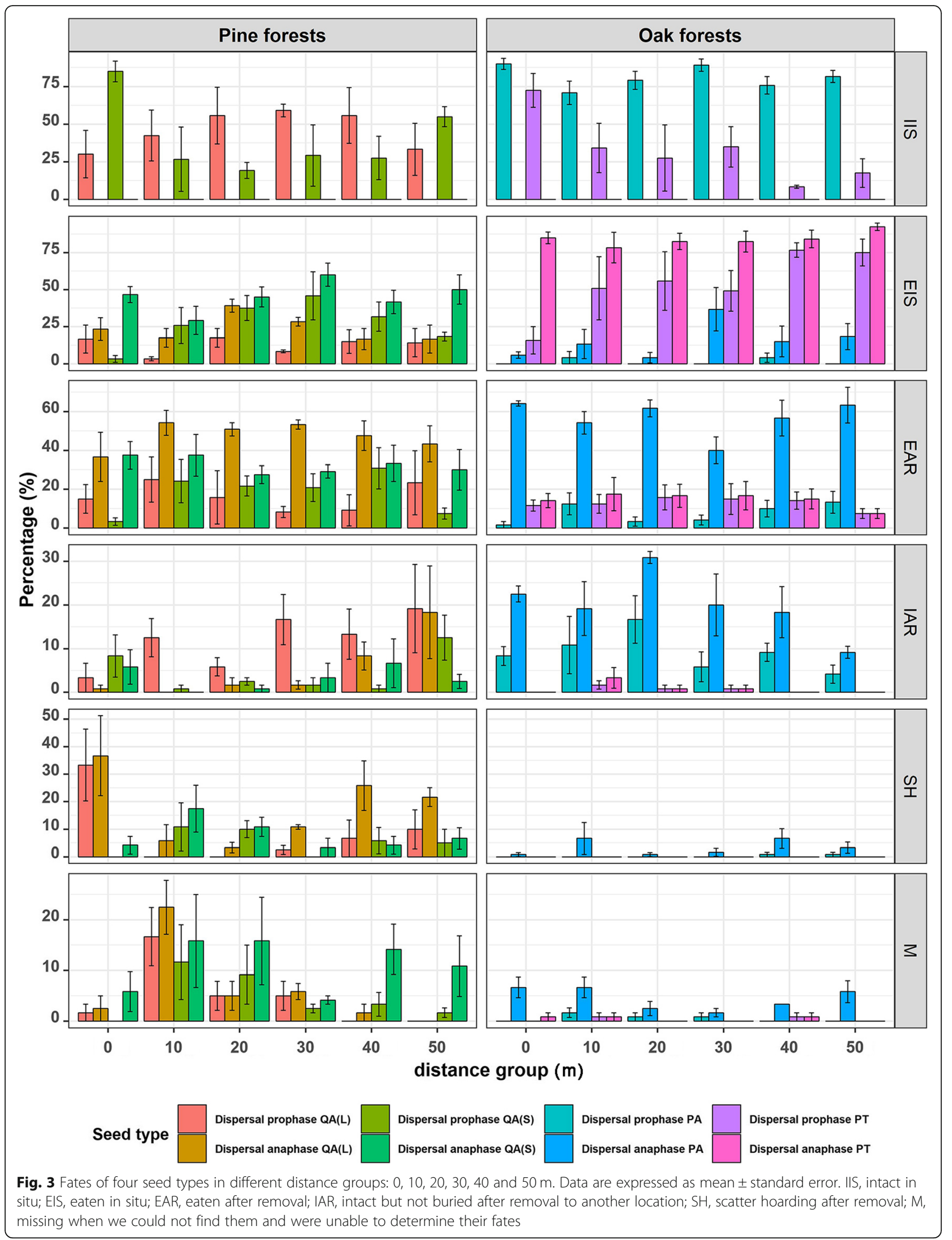




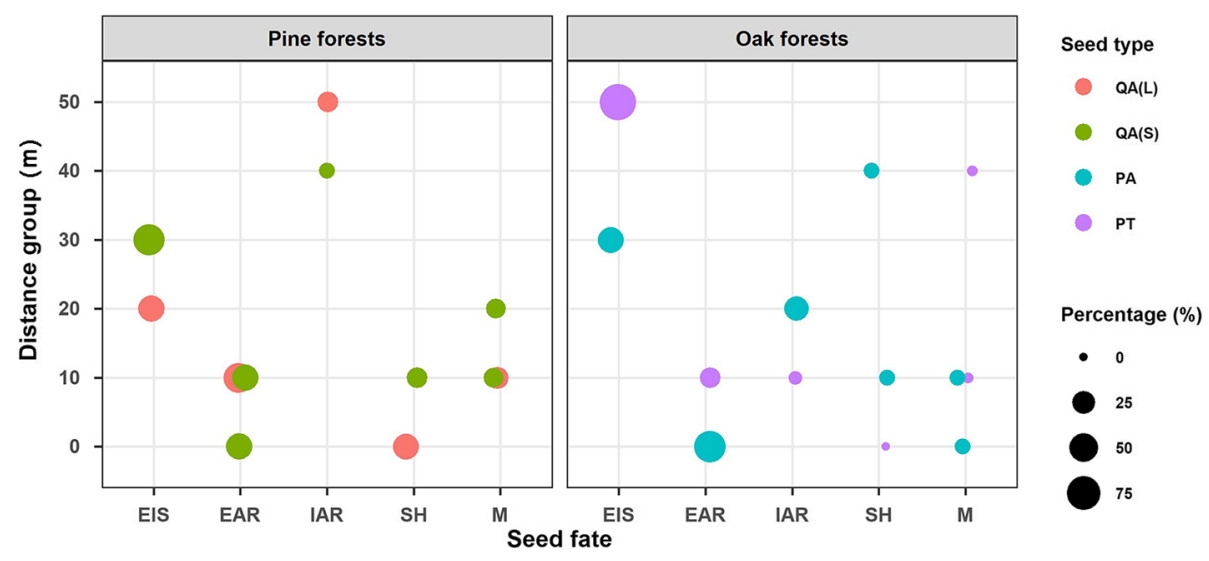

Fig. 4 Distance groups with the maximum seed fate proportions for the four seed types. QA(L), Quercus aliena var. acuteserrata (large); QA(S), Quercus aliena var. acuteserrata (small); PA, Pinus armandii; PT, P. tabuliformis

$P<0.001)$, and the interaction between seed species and distance group was significant in pine forests $(F=$ 12.970, $d f=5, P<0.001$ ) (Fig. 5). In pine forests, large acorns appeared to be moved further than small acorns $(F=16.090, d f=1, P<0.001)$ and the effect was significant at $0 \mathrm{~m}(F=102, d f=1, P<0.001)$. In oak forests, the removal distances of $P$. armandii seeds were markedly longer than those of $P$. tabuliformis seeds $(F=42.580$, $d f=1, P<0.001$ ), and we also found significant differences between the two seed species at all distance groups (all $P<0.05$ ).

The maximum dispersal distances of large Q. aliena var. acuteserrata and small Q. aliena var. acuteserrata seeds were 26.0 and $13.0 \mathrm{~m}$ in pine forests, respectively, and those for $P$. armandii and $P$. tabuliformis seeds were 12.5 and $4.1 \mathrm{~m}$ in oak forests. The maximum dispersal distances of acorns in pine forests were found in the 10 $\mathrm{m}$ distance group. The maximum dispersal distances of $P$. tabuliformis and P. armandii seeds in oak forests were found in the 0 and $10 \mathrm{~m}$ distance groups, respectively.

\section{Scatter hoarding and discard site microhabitats}

The proportions of seeds scatter hoarded under shrubs were higher for large and small Q. aliena var. acuteserrata acorns and $P$. armandii seeds, i.e., $45.60 \%, 71.43 \%$, and $62.50 \%$ of the total number of seeds after scatter hoarding by rodents, respectively (Fig. 6a). A lower proportion of seeds was scatter hoarded in bare land. In addition, we found that over $24 \%$ of the Q. aliena var. acuteserrata seeds were carried to holes by rodents (Fig. 6a). P. tabuliformis seeds were not scatter hoarded, but the scatter-hoarded rates for the other three seed types tended to decrease as the microhabitat changed from complex to simple (shrub to grassland, shrub edge, and bare land) (Fig. 6a). The change in the discard microhabitat was the opposite and all of the P. tabuliformis seeds were discarded in bare land after removal by rodents. The proportions of seeds discarded in bare land were higher for small $Q$. aliena var. acuteserrata, large $Q$. aliena var. acuteserrata, and P. armandii seeds, i.e., $60.87 \%, 45.95 \%$, and $41.67 \%$ of the total seeds discarded by rodents, respectively (Fig. 6b).

\section{Germination of surviving seeds}

The P. tabuliformis seeds were not cached but 205 cached seeds survived in secondary caches according to our final survey, where 165 Q. aliena var. acuteserrata and $1 P$. armandii seeds were cached under the canopy in pine forest, $23 P$. armandii and 16 Q. aliena var. acuteserrata seeds were cached under the canopy in oak forest (Table 3). During 2016, 11 Q. aliena var. acuteserrata seedlings emerged from the tagged seeds within the pine community, i.e., three seedlings under shrubs, seven seedlings at shrub edges, and one seedling in grassland, where the growth vitality levels of these seedlings were moderate, strong, and moderate, respectively (Table 3). By contrast, almost all of cached acorns and $P$. armandii seeds were recovered and subsequently consumed. In July 2017, we found that no Q. aliena var. acuteserrata seedlings had germinated from the surviving tagged seeds.

\section{Discussion}

Seed removal rates of Quercus acorns and Pinus seeds differed after entering pine and oak forests

The seed dispersal process is affected by several factors, including the availability of food resources, environmental pressure, and the size and composition of the disperser community (Lichti et al. 2017). In the current study, we found that the rodent species and capture rates did not differ between pine and oak forests. The seed removal rates by rodents differed for various seed species, but the lack of any difference in the removal of large and small $Q$. aliena var. acuteserrata acorns 

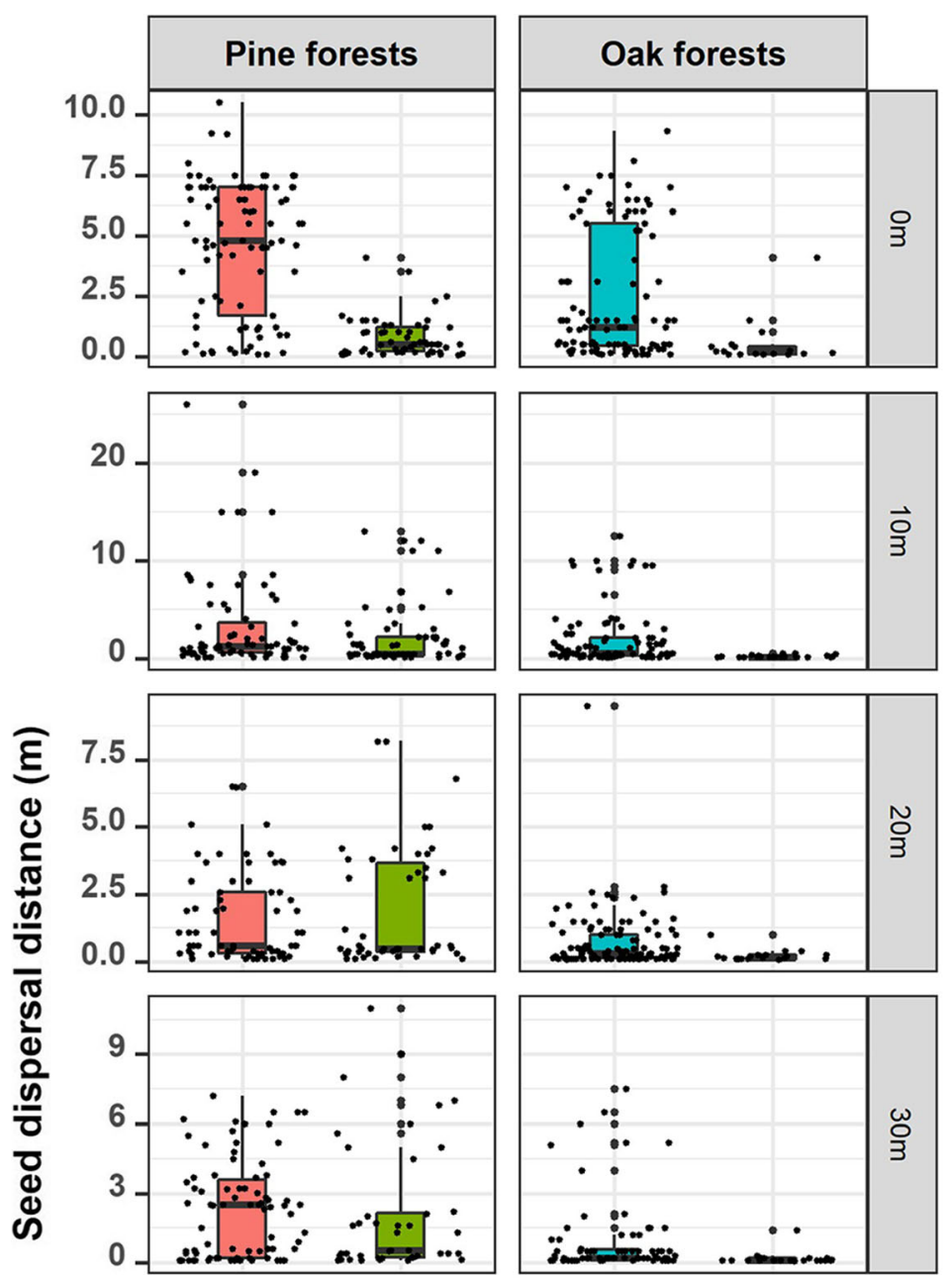

Seed type
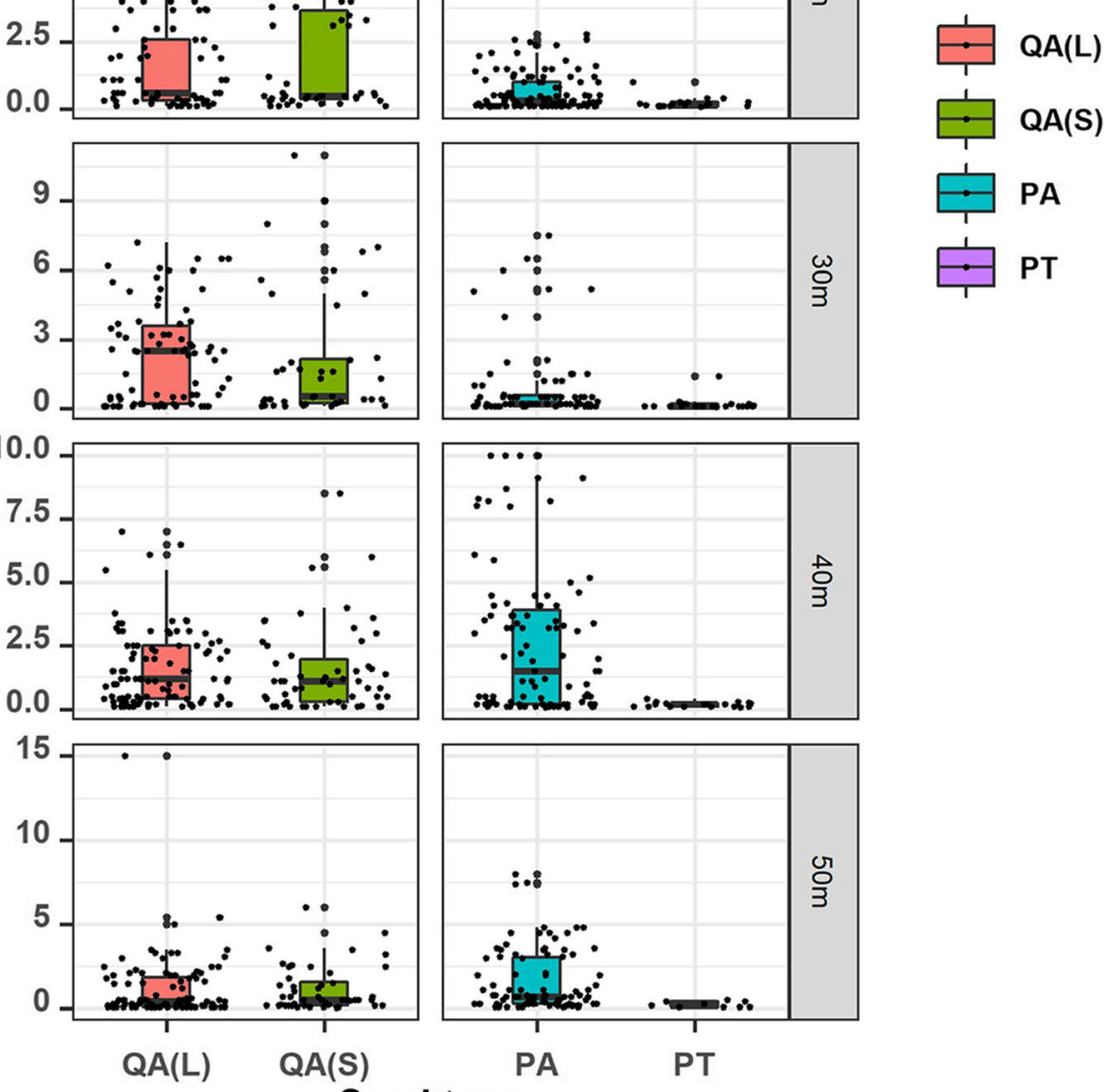

Seed type

Fig. 5 Distributions of the four seed types in different distance groups: 0, 10, 20, 30, 40 and $50 \mathrm{~m}$. QA(L), Quercus aliena var. acuteserrata (large); $\mathrm{QA}(\mathrm{S})$, Quercus aliena var. acuteserrata (small); PA, Pinus armandii; PT, P. tabuliformis 

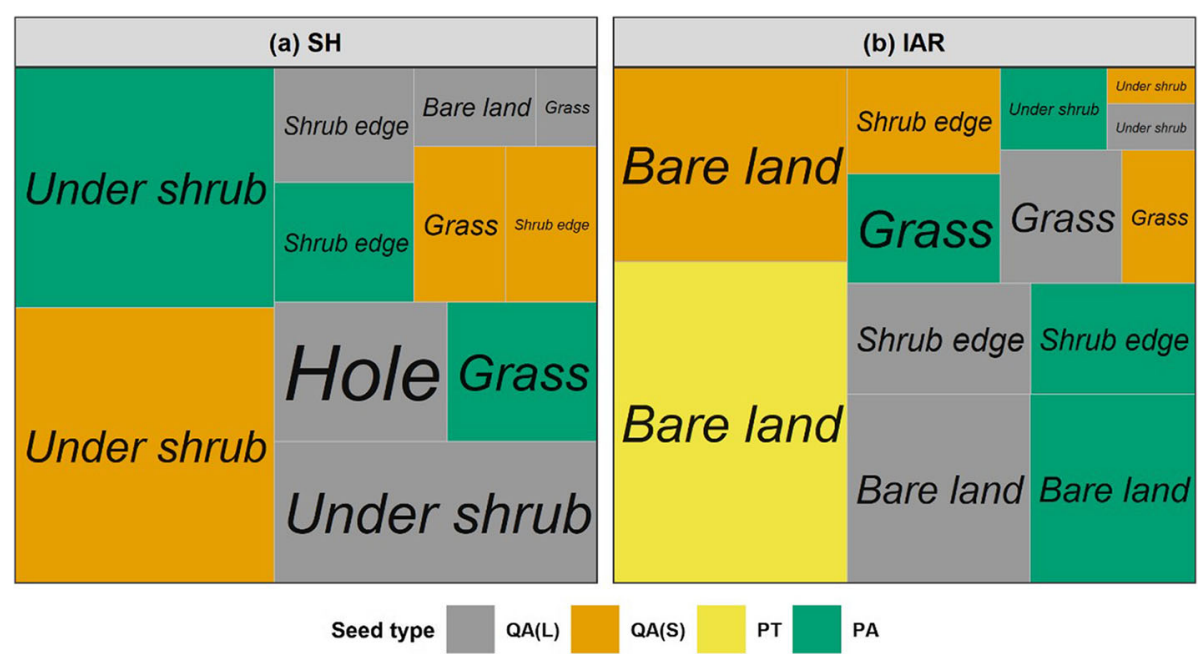

Fig. 6 Scatter hoarding and discarding microhabitat for the four seed types after removal by rodents in the study area. QA(L), Quercus aliena var. acuteserrata (large); QA(S), Quercus aliena var. acuteserrata (small); PA, Pinus armandii; PT, P. tabuliformis. SH, scatter hoarding after removal; IAR, intact but not buried after removal to another location

demonstrates the importance of rodents for effective seed dispersal in pine forests. In addition, the different removal rates for $P$. tabuliformis and $P$. armandii seeds indicate that rodents employ selection strategies and favor specific seeds. These results are consistent with previous reports that small rodents play important roles in seed dispersal (Vander Wall 2003; Xiao et al. 2005; Chang et al. 2012; Yu et al. 2014). We found an acorn have removed by rodent to the tree trunk, and observed Sciurotamias davidianus eaten acorn on the oak tree many times during investigation. S. davidianus was the main disperser involved in long distance seed dispersal, especially in the vertical direction in pine-oak mixed forests. We also found traces of wild pig activity at two seed stations, thereby demonstrating that the composition of the seed dispersers was diverse, and we could not exclude the possibility that birds, ants, and pheasants may have participated in the seed dispersal process (Cheng et al. 2010; Soler et al. 2017), although their effects were probably negligible compared with small rodents (Chang et al. 2012). Our results showed that the removal rate was lower than that reported by $\mathrm{Yu}$ et al. (2014) in the same research region, this could be caused by the field seed release experiments were conducted during the seed rain in a mast year (Table 2) and the widely accepted predator satiation hypothesis states that the seed removal rate decreases in mast years (Vander Wall 2002; Li and Zhang 2007; Borchert and Defalco 2016).

Different seed fates of Quercus acorns and Pinus seeds in pine and oaks forests affect the regeneration modes Animals make choices regarding the seeds allocated to consumption or storage, seed preparation, and cache placement in response to the traits of particular seeds (Lichti et al. 2017; Wang and Corlett 2017). Thus, seed traits such as the seed size, shape, shell thickness and hardness, energy density (fat, protein, digestive inhibitors, etc.), dormancy, insect infestation, and seed secondary compounds (e.g., tannin) significantly influence the seed fates and disperser behavior (Acamovic and Brooker 2005; Zhou et al. 2013; Yu et al. 2015; Smallwood et al. 2016; Bartlow et al. 2017). We found differences in the seed fates for Q. aliena var. acuteserrata acorns in pine forests and $P$. tabuliformis and P. armandii seeds in oak forests, where the Q. aliena var. acuteserrata acorns had the most

Table 3 Germination of surviving seeds in pine and oak forests

\begin{tabular}{|c|c|c|c|c|c|c|c|}
\hline \multirow[t]{2}{*}{ Species } & \multirow{2}{*}{$\begin{array}{l}\text { Total cached seeds } \\
\text { (in 2015) }\end{array}$} & \multicolumn{5}{|c|}{ Seed germination in different microhabitat type (in 2016) } & \multirow{2}{*}{$\begin{array}{l}\text { Survival } \\
\text { (in 2017) }\end{array}$} \\
\hline & & Under shrub & Shrub edge & Hole & Grassland & Bare land & \\
\hline $\begin{array}{l}\text { Quercus aliena } \\
\text { var. acuteserrata }\end{array}$ & 181 (large and small) & 3 & 7 & 0 & 1 & 0 & 0 \\
\hline Pinus tabuliformis & 0 & - & - & - & - & - & - \\
\hline P. armandii & 24 & - & - & - & - & - & - \\
\hline \multicolumn{2}{|c|}{ Seedling growth vitality } & Moderate & Strong & - & Moderate & - & - \\
\hline
\end{tabular}


evident removal and scatter-hoarding patterns. By contrast, the $P$. tabuliformis and $P$. armandii seeds were heavily predated by rodents, as shown in previous studies ( $\mathrm{Yu}$ et al. 2014). We found that the proportions of EAR, IAR, and $\mathrm{SH}$ were higher for large Q. aliena var. acuteserrata acorns than small $Q$. aliena var. acuteserrata acorns. It has been widely reported that rodents have a preference for foraging large $Q$. aliena var. acuteserrata acorns (Wang and Chen 2009). Our results also showed that the proportions of EAR, IAR, and SH were much lower for $P$. tabuliformis seeds than $P$. armandii seeds, and P. tabuliformis seeds were eaten almost entirely in situ by rodents, which may be attributed to the $P$. armandii seed traits due to their thick and hard shells. The energy consumption and predation risks associated with the predation process for rodents are also issues that cannot be ignored (Steele et al. 2015; Bartlow et al. 2017). Our results partly agree with those obtained in previous studies, which showed that most seeds with thick and hard shells were eaten after their removal by rodents (Yan et al. 2012; Wang et al. 2017). In our study, only a few large Q. aliena var. acuteserrata acorns and $P$. armandii seeds were eaten at the seed stations, thereby suggesting that large and high nutritional value seeds were more likely to be cached for future use. It should be noted that eating seeds in situ is time consuming and it could lead to a high predation risk for rodents. In addition, most of the pine seeds in oak forests were eaten by rodents whereas more oak seeds were cached in pine forests. Therefore, this difference can be explained by the seed traits, animal foraging decisions, and the survival context where the decisions were made (Lichti et al. 2017).

After comparing the different distance groups, we found that the seed dispersal patterns differed in the dispersal prophase and anaphase in pine and oak forests. We found that seeds were removed rapidly by rodents in all of the distance groups in the dispersal prophase. These results support the hypothesis that rodents employed a rapid sequestering seed harvest strategy for a limited food resource in order to make them unavailable to competitors, and they spaced out the caches to make them less vulnerable to pilferage by other rodents (Jenkins and Peters 1992). Moreover, we found that the seed fates differed significantly in different distance groups, possibly because the various microhabitats around the seed stations affected the dispersal decisionmaking processes of rodents. The proportions of scatterhoarded Q. aliena var. acuteserrata acorns were significantly higher in the $0 \mathrm{~m}$ and $10 \mathrm{~m}$ distance groups (edge between pine forests and oak forests) compared with the other distance groups in pine forests, and higher predation rates were found in the $20 \mathrm{~m}$ and $30 \mathrm{~m}$ distance groups compared with the other distance groups (Figs. 3, 5). Therefore, the regions located away from the edge
(20 $\mathrm{m}$ and $30 \mathrm{~m}$ distance groups) were relatively safe from predation by rodents in the pine forests. However, the $0-10 \mathrm{~m}$ distance group had a higher removal rate, which indicates that there was a higher predation risk (low vegetation coverage) or fierce competition for food resources at a distance of $0-10 \mathrm{~m}$. In our study, there was an area of low vegetation coverage caused by an artificial disturbance (picking medicinal herbs) in the edge between pine forests and oak forests. Similarly, previous studies also showed that complex vegetation conditions can effectively reduce the foraging risk (Jones et al. 2003; Fedriani and Manzaneda 2005). Furthermore, although the habitat structure has been shown to influence seed dispersal (Kellner et al. 2016), the effects of the understory cover might be complex, and thus further research is required to determine whether diverse surface vegetation influences the seed germination process.

The dispersal distance indirectly reflects the value of food resources to animals (Dally et al. 2006). In the present study, the dispersal distances were much longer for Quercus acorns in pine forests than those for Pinus seeds in oak forests, and the dispersal distance was mostly short in the dispersal prophase. These results conform with models that explain the evolution of rodent caching behavior based on the influence of the value of food resources, thereby predicting how rodents should distribute their caches to avoid cache pilferage (Vander Wall and Jenkins 2003; Dally et al. 2006). In simple terms, food with low nutritional value should be stored near the resource site, whereas food with high nutritional value is more likely to be cached away from the resource site to prevent it from being stolen by competitors. Thus, the dispersal strategies of rodents can affect the spatial distribution pattern and survival mode of seeds, especially for Quercus acorns, where they can allow them to avoid high mortality below the parent tree. Indeed, dispersal by rodents can greatly enhance the dispersal distance of Quercus acorns and it has important effects on seed germination and seedling growth. In addition, we found that the amount and distance of seed transport were significantly higher in the $0 \mathrm{~m}$ distance group compared with the other groups, thereby indicating that the animals at the forest edge were active and they competed strongly for food resources (Yu et al. 2018).

\section{Seedling survival associated with the integrated effects of microhabitats on the seed dispersal process and long- term seedling success}

The risk of predation also affects cache placement (Lichti et al. 2017) and it can help to regulate plant-animal interactions by influencing how prey animals use their habitats (Laundrã et al. 2014). In particular, rodents respond to variations in anti-predator cover by 
preferentially moving seeds into secluded shelter (Zhang et al. 2013) or by deliberately placing caches in risky locations (Steele et al. 2014; Steele et al. 2015). Seeds are passively dispersed due to the predatory behavior of animals to generate unique and complex distributions and regeneration patterns. The microhabitats in the scatterhoarding sites for the surviving seeds indicated that at least at a small scale, rodents intentionally removed seeds to specific microhabitat types, rather than distributing them randomly, and similar results have been obtained previously (Zhang and Zhang 2008; Zhang et al. 2013). Most of the Pinus seeds were discarded after their removal by rodents in bare land, but they were available for subsequent seed germination. Most, but not all, of the cache microhabitats were unsuitable for seedling germination and only a few Q. aliena var. acuteserrata seedlings germinated from seeds cached by rodents in the second year. We found that the number of seedlings was slightly higher in bare land compared with the other scatter-hoarding sites. Previous studies also showed that bare land with adequate light, soil, and space resources under the canopy can facilitate seed germination and seedling establishment (Zhang et al. 2013). However, our results suggest that due to the conflicting demands of rodents for caching seeds in more secure sites, the rodents might trade-off an increased exposure to predation risk for lower pilferage risks (Lichti et al. 2017).

We also found that the different microhabitats appeared to influence the germination of different seed types and seedling establishment. Many plants exhibit subtle differences in their environmental preferences for seed germination and seedling growth (e.g., Q. aliena var. acuteserrata seedlings are shade tolerant but obvious competition for light and space occurs when they become saplings), and thus the optimal microhabitats for seed germination may not favor subsequent seedling growth. According to previous studies, there is great uncertainty about whether animal-preferred cache sites might facilitate long-term seedling establishment and growth (Briggs et al. 2009) because the microhabitat conditions in dispersal sites are not always ideal for seedling establishment and growth (Spiegel and Ran 2012; Zhang et al. 2013). Compared with the other microhabitat types, shrub edges have superior light and soil conditions, and they are characterized by low interspecific competition (Zhang 2001). Our results indicate that seeds dispersed to bare land and shrub edge sites had higher rates of germination and establishment. However, the seedlings did not survive in the later stages because we found that all of the seedlings were dead in 2017 due to various unknown effects, such as environmental factors, species features, and interspecific competition, although we suspect that extreme weather (e.g., blizzards and low temperatures) prevented the seedlings from surviving the winter. In addition, it should be noted that the drilled seeds have a greater risk of infection, which will reduce their germination rate and make the relationship between rodent-mediated seed dispersal and seedling establishment more complicated and uncertain.

\section{Conclusions}

Quercus and Pinus seeds had different fates after their bidirectional dispersal in pine and oak forests, respectively. Many Pinus seeds were heavily eaten by rodents, which strongly determined the lack of Pinus seedlings in oak forests. The predation pressure by rodents on the seeds of Pinus species limited the germination of seeds and seedling establishment in oak forests. In addition, the specific preferences for seed scatter hoarding, predation, and discarding in certain microhabitats by rodents led to positive conditions for seed germination. The impacts of forest rodents on seed dispersal were as expected, it seems to act as a "promoter" for the community competition. The different seed fates after their bidirectional dispersal could affect the differences in natural regeneration between pine and oak forests, and they might increase the recruitment rates for oak at the edge of an adjacent community. However, the contributions of rodents in terms of the dispersal of Pinus seeds into oak forests cannot be ignored (due to the high $P$. armandii seed caching rates and enhanced communication between plant communities). Rodent-mediated seed dispersal unintentionally affects the competition between plant communities, and thus the natural regeneration and plant community dynamics of pine and oak forests are complex in the Qinling Mountains where stable pine-oak mixed forest is the main landscape pattern.

\section{Supplementary information}

Supplementary information accompanies this paper at https://doi.org/10 1186/s40663-020-00270-z.

Additional file 1: Figure S1. Schematic diagram showing the plots employed for the seed dispersal experiment and seed traps.

\section{Acknowledgments \\ We would like to thank Qinling National Forest Ecosystem Research Station at Huoditang, Ningshaan County, Shaanxi Province and Xiaolongshan National Forest Ecosystem Research Station at Tianshui City, Gansu Province for support during our field investigation. We also thank Dr. Yue Pang and Qinglin Teng provided important help in the field.}

\section{Authors' contributions}

All authors have contributed to develop the research work. HK, MC and DW designed the experiment; HK and MC performed the experiments; SL and ZC analyzed the data; XZ designed and finished the figures; HK wrote the paper. All authors have read and approved the final manuscript.

\section{Funding}

This study was funded by the National Natural Science Foundation of China (No. 31470644). 


\section{Availability of data and materials}

The datasets used and/or analyzed during the current study are available from the corresponding author on reasonable request.

\section{Ethics approval and consent to participate}

All applicable international, nation, and/or institutional guidelines for the care and care of animal were followed.

\section{Consent for publication}

Not applicable.

\section{Competing interests}

The authors declare that they have no competing interests.

\section{Author details}

'College of Forestry, Northwest A \& F University, Yangling 712100, China. ${ }^{2}$ College of Art and Design, Xi'an University of Technology, Xi'an 710054, China.

Received: 15 June 2020 Accepted: 9 October 2020

Published online: 19 October 2020

\section{References}

Acamovic T, Brooker JD (2005) Biochemistry of plant secondary metabolites and their effects in animals. Proc Nutr Soc 64:403-412

Bartlow AW, Agosta SJ, Curtis R, Yi X, Steele MA (2017) Acorn size and tolerance to seed predators: the multiple roles of acorns as food for seed predators, fruit for dispersal and fuel for growth. Integr Zool 13(3):251-266. https://doi. org/10.1111/1749-4877.12287

Bergeron P, Réale D, Humphries MM, Garant D (2011) Anticipation and tracking of pulsed resources drive population dynamics in eastern chipmunks. Ecology 92:2027-2034

Borchert MI, Defalco LA (2016) Yucca brevifolia fruit production, predispersal seed predation, and fruit removal by rodents during two years of contrasting reproduction. Am J Bot 103:830-836

Briggs JS, Wall SBV, Jenkins SH (2009) Forest rodents provide directed dispersal of Jeffrey pine seeds. Ecology 90:675-687

Chang G, Jin TZ, Pei JF, Chen XN, Zhang B, Shi ZJ (2012) Seed dispersal of three sympatric oak species by forest rodents in the Qinling Mountains, Central China. Plant Ecol 213:1633-1642

Cheng Z, Wauters LA, Van Dongen S, Mari V, Romeo C, Martinoli A, Preatoni D, Tosi G (2010) Annual variation in predation and dispersal of Arolla pine (Pinus cembra L.) seeds by Eurasian red squirrels and other seed-eaters. Forest Ecol Manag 260:587-594

Clair SBS, O'Connor R, Gill R, Mcmillan B (2016) Biotic resistance and disturbance: rodent consumers regulate post-fire plant invasions and increase plant community diversity. Ecology 97:1700-1711

Dally JM, Clayton NS, Emery NJ (2006) The behaviour and evolution of cache protection and pilferage. Anim Behav 72:13-23

Dylewski Ł, Ortega YK, Bogdziewicz M, Pearson DE (2020) Seed size predicts global effects of small mammal seed predation on plant recruitment. Ecol Lett 23:1027-1033

Fedriani JM, Manzaneda AJ (2005) Pre- and postdispersal seed predation by rodents: balance of food and safety. Behav Ecol 16:1018-1024

Garcia D, Banuelos MJ, Houle G (2002) Differential effects of acorn burial and litter cover on Quercus rubra at the limit of its range in eastern North America. Can J Bot 80:1115-1120

Gracia M, Retana J, Roig P (2002) Mid-term successional patterns after fire of mixed pine-oak forests in NE Spain. Acta Oecol-Int J Ecol 23:405-411. https://doi.org/10.1016/s1146-609x(02)01169-4

Jenkins SH, Peters RA (1992) Spatial patterns of food storage by Merriam's kangaroo rats. Behav Ecol 3:60-65

Jones FA, Peterson CJ, Haines BL (2003) Seed predation in Neotropical premontane pastures: site, distance, and species effects. Biotropica 35:219-225

Kang HB, Zheng YY, Liu ST, Chai ZZ, Chang MJ, Hu YN, Li G, Wang DX (2017) Population structure and spatial pattern of predominant tree species in a pine-oak mosaic mixed forest in the Qinling Mountains, China. J Plant Interact 12:78-86. https://doi.org/10.1080/17429145.2017.1283069

Kellner KF, Lichti NI, Swihart RK (2016) Midstory removal reduces effectiveness of oak (Quercus) acorn dispersal by small mammals in the central hardwood Forest region. Forest Ecol Manag 375:182-190
Laundrã JW, Hernández L, Medina PL, Campanella A, López-Portillo J, GonzálezRomero A, Grajales-Tam KM, Burke AM, Gronemeyer P, Browning DM (2014) The landscape of fear: the missing link to understand top-down and bottomup controls of prey abundance? Ecology 95:1141-1152

Li HJ, Zhang ZB (2003) Effect of rodents on acorn dispersal and survival of the Liaodong oak (Quercus liaotungensis Koidz.). Forest Ecol Manag 176:387-396

Li HJ, Zhang ZB (2007) Effects of mast seeding and rodent abundance on seed predation and dispersal by rodents in Prunus armeniaca (Rosaceae). Forest Ecol Manag 242:511-517. https://doi.org/10.1016/j.foreco.2007.01.063

Lichti NI, Steele MA, Swihart RK (2017) Seed fate and decision-making processes in scatter-hoarding rodents. Biol Rev 92:474-504

Lonsdale WM (1999) Global patterns of plant invasions and the concept of invasibility. Ecology 80:1522-1536. https://doi.org/10.1890/00129658(1999)080[1522:Gpopia]2.0.Co;2

Mendes CP, Ribeiro MC, Galetti M (2016) Patch size, shape and edge distance influence seed predation on a palm species in the Atlantic forest. Ecography 39:465-475

Santos-Filho M, Peres CA, Sanaiotti DJDSM (2012) Habitat patch and matrix effects on small-mammal persistence in Amazonian forest fragments. Biodivers Conserv 21:1127-1147

Smallwood PD, Steele MA, Faeth SH (2016) The ultimate basis of the caching preferences of rodents, and the oak-dispersal syndrome: tannins, insects, and seed germination. Am Zool 41:840-851

Soler R, Espelta JM, Lencinas MV, Peri PL, Martínez Pastur G (2017) Masting has different effects on seed predation by insects and birds in antarctic beech forests with no influence of forest management. Forest Ecol Manag 400:173180. https://doi.org/10.1016/j.foreco.2017.06.014

Spiegel O, Ran N (2012) Empirical evaluation of directed dispersal and densitydependent effects across successive recruitment phases. J Ecol 100:392-404

Steele MA, Contreras TA, Hadjchikh LZ, Agosta SJ, Smallwood PD, Tomlinson CN (2014) Do scatter hoarders trade off increased predation risks for lower rates of cache pilferage? Behav Ecol 25:206-215

Steele MA, Rompré G, Stratford JA, Zhang H, Suchocki M, Marino S (2015) Scatterhoarding rodents favor higher predation risks for cache sites: the potential for predators to influence the seed dispersal process. Integr Zool 10:257-266

Stone R (2006) Ecology: a threatened nature reserve breaks down Asian borders. Science 313:1379-1380

Vander Wall SB (1990) Food hoarding in animals. University of Chicago Press, Chicago

Vander Wall SB (1993) Cache site selection by chipmunks (Tamias spp.) and its influence on the effectiveness of seed dispersal in jeffrey pine (Pinus jeffreyi). Oecologia 96:246-252

Vander Wall SB (2002) Masting in animal-dispersed pines facilitates seed dispersal. Ecology 83:3508-3516

Vander Wall SB (2003) Effects of seed size of wind-dispersed pines (Pinus) on secondary seed dispersal and the caching behavior of rodents. Oikos 100:25-34

Vander Wall SB (2010) How plants manipulate the scatter-hoarding behaviour of seed-dispersing animals. Philos Trans R Soc Lond Ser B Biol Sci 365:989-997

Vander Wall SB, Beck MJ (2012) A comparison of frugivory and scatter-hoarding seed-dispersal syndromes. Bot Rev 78:10-31. https://doi.org/10.1007/s12229011-9093-9

Vander Wall SB, Jenkins SH (2003) Reciprocal pilferage and the evolution of foodhoarding behavior. Behav Ecol 14:656-667

Wang B, Chen J (2009) Seed size, more than nutrient or tannin content, affects seed caching behavior of a common genus of old world rodents. Ecology 90:3023-3032

Wang B, Corlett RT (2017) Scatter-hoarding rodents select different caching habitats for seeds with different traits. Ecosphere 8:e01774

Wang J, Yan QL, Yan T, Song Y, Sun YR, Zhu JJ (2017) Rodent-mediated seed dispersal of Juglans mandshurica regulated by gap size and within-gap position in larch plantations: implication for converting pure larch plantations into larch-walnut mixed forests. Forest Ecol Manag 404:205-213. https://doi. org/10.1016/j.foreco.2017.08.033

Whitmore TC (1978) Gaps in the forest canopy. Tropical trees as living systems. Cambridge University Press, New York

Wróbel A, Zwolak R (2019) Habitat-dependent seed dispersal of an introduced tree species by native rodents. Forest Ecol Manag 433:563-568

Xiao ZS, Jansen PA, Zhang ZB (2006) Using seed-tagging methods for assessing post-dispersal seed fate in rodent-dispersed trees. Forest Ecol Manag 223:1823. https://doi.org/10.1016/j.foreco.2005.10.054 
Xiao ZS, Krebs CJ (2015) Modeling the costs and benefits of seed scatterhoarding to plants. Ecosphere 6:1-8

Xiao ZS, Zhang ZB, Wang YS (2005) The effects of seed abundance on seed predation and dispersal by rodents in Castanopsis fargesii (Fagaceae). Plant Ecol 177:249-257

Yan QL, Gang Q, Zhu JJ, Sun YR (2016) Variation in survival and growth strategies for seedlings of broadleaved tree species in response to thinning of larch plantations: implication for converting pure larch plantations into larchbroadleaved mixed forests. Environ Exp Bot 129:108-117

Yan XF, Yu YC, Zhou LB, Zhou YF (2012) Seed predation and removal of Quercus wutaishanica, Prunus salicina and Pinus armandii by rodents in the Liupan Mountains. Biodivers Sci 20:427-436

Yang Y, Zhang M, Yi X (2016) Small rodents trading off forest gaps for scatterhoarding differs between seed species. Forest Ecol Manag 379:226-231. https://doi.org/10.1016/j.foreco.2016.08.005

Yi XF, Zhang ZB (2008) Seed predation and dispersal of glabrous filbert (Corylus Heterophylla) and pilose filbert (Corylus Mandshurica) by small mammals in a temperate forest, Northeast China. Plant Ecol 196:135-142

Yu F, Shi XX, Wang DX, Yi XF, Fan DF, Guo TD, Lou YG (2015) Effects of insect infestation on Quercus aliena var. acuteserrata acorn dispersal in the Qinling Mountains, China. New Forest 46:51-61

Yu F, Shi XX, Yi XF, Ma JM (2018) Rodent-mediated seed dispersal shapes species composition and recruitment dynamics in ecotones. Front Plant Sci 9:1911. https://doi.org/10.3389/fpls.2018.01911

Yu F, Wang DX, Shi XX, Yi XF, Huang QP, Hu YN (2013) Effects of environmental factors on tree seedling regeneration in a pine-oak mixed forest in the Qinling Mountains, China. J Mt Sci 10:845-853

Yu F, Wang DX, Yi XF, Shi XX, Huang YK, Zhang HW, Zhang XP (2014) Does animal-mediated seed dispersal facilitate the formation of Pinus armandiiQuercus aliena var. acuteserrata forests? PLoS One 9:396-401

Zhang HM, Luo Y, Steele MA, Yang Z, Wang Y, Zhang ZB (2013) Rodent-favored cache sites do not favor seedling establishment of shade-intolerant wild apricot (Prunus armeniaca Linn.) in northern China. Plant Ecol 214:531-543

Zhang HM, Zhang ZB (2008) Endocarp thickness affects seed removal speed by small rodents in a warm-temperate broad-leafed deciduous forest, China. Acta Oecol 34:285-293

Zhang ZB (2001) Effect of burial and environmental factors on seedling recruitment of Quercus liaotungensis Koidz. Acta Ecol Sin 21:374-384

Zhou LB, Yan XF, Wang JL, Zhou YF (2013) Predation and removal of rodents on the seeds with different size and pericarp traits. Chin J Appl Ecol 24:2325-2332

\section{Submit your manuscript to a SpringerOpen ${ }^{\circ}$ journal and benefit from:}

- Convenient online submission

- Rigorous peer review

- Open access: articles freely available online

- High visibility within the field

- Retaining the copyright to your article

Submit your next manuscript at $\boldsymbol{\nabla}$ springeropen.com 